Ridder, D. de, Kerssens, J. Owing to the force of circumstances? The impact of situational features and personal characteristics on coping patterns across situations. Psychology \& Health: 2003, 18(2), 217-236

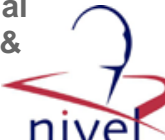

\begin{tabular}{|l|l|}
\hline $\begin{array}{l}\text { Postprint } \\
\text { Version }\end{array}$ & 1.0 \\
\hline Journal website & http://www.tandfonline.com/doi/abs/10.1080/0887044021000044242 \\
\hline Pubmed link & \\
\hline DOI & $10.1080 / 0887044021000044242$ \\
\hline
\end{tabular}

This is a NIVEL certified Post Print, more info at http://www.nivel.eu

\title{
Owing to the Force of Circumstances? The Impact of Situational Features and Personal Characteristics on Coping Patterns Across Situations
}

\author{
DENISE DE RIDDER ${ }^{\mathrm{A}, *}$ AND JAN KERSSENS ${ }^{\mathrm{B}}$
}

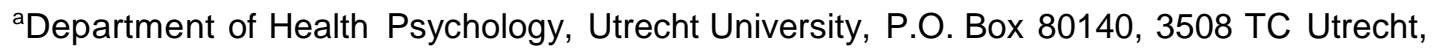
The Netherlands;

${ }^{b}$ Netherlands Institute of Health Services Research, Utrecht, The Netherlands

The objective of this study is to quantify situational impacts on coping compared to the impact of personal characteristics. A facet design was used to systematically vary three situational features (ambiguity, social context, and concern at stake) in twenty vignettes of stressful situations that were presented to a sample of 430 healthy persons to elicit coping responses. In addition, relevant personal characteristics (mental health, self-esteem, perceived social support, and dispositional coping styles) were assessed. A series of variance component analyses demonstrated that for eight types of coping behavior, variability within individuals across situations was larger than variability between individuals. Multilevel analyses, accounting for both the person level and the situation level in the data, were employed to identify the situational features and personal characteristics that were responsible for situation-related variance and person-related variance respectively. Results demonstrate that all three situational features proved significant contributors to differentiated situation-specific coping patterns. No single personal factor could be identified as relevant in shaping coping behaviors, although the combined impact of personal factors explained a considerable amount of variance at the personal level. It is concluded that the study of situational features is a promising way to understand in which way situations shape coping behavior, and may be helpful in guiding the development of coping scales tailored to specific situations.

Coping is one of the most researched topics in health psychology and a key concept in understanding adaptation to a wide range of stressful circumstances. An intriguing issue in coping research pertains to the question to what extent coping responses are an expression of dispositional preferences and to what extent they are triggered by 
Ridder, D. de, Kerssens, J. Owing to the force of circumstances? The impact of situational features and personal characteristics on coping patterns across situations. Psychology \& Health: 2003, 18(2), 217-236

situational demands. This is an important question, as recent analyses of the present crisis in coping research point to dispositional assessment of coping as one of the causes of our limited understanding of behavioral adaptive processes (Somerfield and McCrae, 2000; Tennen et al., 2000). The debate on situational versus dispositional coping was introduced by the work of Lazarus and his colleagues, articulating a transactional view on coping in which the subjective appraisal of demanding situations and available coping resources was assumed to shape coping responses - thus advocating a so-called situation-specific approach to adaptive behaviors (Lazarus and Folkman, 1984). The theoretical notion that the behavioral expression of dispositional coping styles may be constrained by situational characteristics, made a great appeal to coping researchers (cf. De Ridder, 1997). However, some authors have questioned whether the complex assessment of situational coping had surplus value compared with traditional dispositional measures; that is, would lead to a more accurate account of coping behavior and to better predictions of adaptive outcomes (Endler and Parker, 1990).

A convincing argument in favor of a situation-specific approach is that it provides a more accurate description of the way people cope when confronted with stress than a dispositional approach may reveal. Comparing coping responses across situations shows a fair degree of variability in the way people deal with different situations (McCrae, 1984; Folkman et al., 1986a; Mattlin et al., 1990; Lester et al., 1994; Stewart and Schwarzer, 1996). For example, a majority of cancer patients reported that they did not have a primary coping strategy (operationalized as the strategy used $5 \%$ more than any other strategy); in fact, most patients reported to employ a mix of strategies when confronted with stress (Dunkel-Schetter et al., 1992). As variability in coping seems to be the rule rather than the exception, it has even been suggested that lack of variability is an expres- sion of rigidity in applying the same strategies regardless of situational demands (Lester et al., 1994; Schwartz et al., 1998) and that such a pattern, demonstrating un-flexibility rather than consistency, is to be found in people who cannot discriminate between categories of events (Cheng et al., 1999). A second argument in favor of a situation-specific approach is that such assessments make a better predictor of adaptive outcomes. Individuals constantly alter their behavior in response to changes in stressful situations (Neufeld, 1999); and as our environment is ever changing, adaptiveness of coping flexibility is implied.

Individuals who can utilize a greater repertoire of strategies may be more flexible and thus have better chances of choosing the 'right' strategy than those who stick to a favorite coping style (Mattlin et al., 1990; Vitaliano et al., 1990; Lester et al., 1994; Cheng, 2001). In spite of these promising findings, we argue that the situationspecific approach to coping has not demonstrated its entire potential. The major unresolved issue in this area pertains to the question which situational characteristics are relevant for explaining coping responses (cf. Aldwin and Stokols, 1988; Bensing et al., 2002). The majority of so-called situation-specific measures do not provide an answer to this question as they instruct respondents to bear a recent stressful experience in mind when endor- sing coping items. Compared to dispositional assessments, this approach may yield more valid measures of what people actually do when confronted with stress, but they do not reveal much about situational impact, as situations are both implicit and variable across subjects. Another way of obtaining situation-specific measures is to study coping in a group of people confronted with the same event (e.g., an examination; Folkman and Lazarus, 1985; 
Ridder, D. de, Kerssens, J. Owing to the force of circumstances? The impact of situational features and personal characteristics on coping patterns across situations. Psychology \& Health: 2003, 18(2), 217-236

cf. Carver and Scheier, 1994). Although this approach allows for a comparison of coping across individuals dealing with the same event, situational features still remain implicit. The absence of knowledge on situational features relevant for the coping process may be due to a major assumption of the transactional approach to coping, stating that situational characteristics need not to be assessed separately as they are already present in subjective appraisal of the situation (Lazarus and Folkman, 1984). Considering subjective appraisals as the start of the coping process, the transactional approach has demonstrated that such appraisals indeed influence coping responses (Folkman and Lazarus, 1980; McCrae, 1984; Forsythe and Compas, 1987). However, this knowledge has not contributed to an understanding of which situational features evoke subjective appraisals of stress and how such features may shape coping responses.

\section{PRESENT STUDY}

The present study aims to clarify the nature of situation-specific coping by substantiating situational impacts on coping compared to the impact of personal characteristics. A second objective concerns the identification of situational and personal features that account for both types of influence. As many studies have already researched the impact of personal characteristics on coping, we will not discuss them here and include those characteristics that have been shown to be relevant for coping: mental health, self-esteem, perceived social support, and dispositional coping styles (Lazarus and Folkman, 1984; cf. Hobfoll, 2001). With regard to situational characteristics, the situation is different, as very few studies have attempted to categorize them. A major issue of this study is to identify situational features that can be assessed independently of subjective appraisal and bear relevance for coping. Three situational features that meet these criteria are proposed: concern at stake, ambiguity, and social context. The concept of concerns is prominent in transactional coping theory (Lazarus and Folkman, 1984) and subsequent work on emotions and stress (Lazarus, 1991). As concerns represent important strivings, it is clear that situations that impose threat to concerns can be considered a source of stress. Situations that put concerns at stake are, therefore, assumed to create 'action-preparedness' (cf. Frijda, 1986; Lazarus, 1991). In addition, there is some evidence that the type of concern put at stake by a stress- ful situation affects coping responses (Folkman et al., 1986b).

To what extent should concerns be considered 'objective' features of situations that exist independent of subjective appraisals of situations? According to Frijda (1986), concerns are of a layered nature as they refer to common values and goals that are widely shared and recognized (source concern) and at the same time refer to a personalized counterpart (surface concern), depending on the individual's actual life situation, personality, and beliefs. An example may clarify the layered nature of concerns. For most people, affiliation with others is an important value and, as such, refers to the source concern of attachment. The actual surface concern may be represented by a sense of belonging in an intimate relationship for some and by feeling acknowledged by the community for others (Frijda, 1986). In the present study, five types of concerns will be distinguished, each of which may affect subsequent coping responses: attachment (Folkman et al., 1986b), control (Folkman, 1984; Paterson and Neufeld, 1987), predictability (Paterson and Neufeld, 1987; Lazarus, 1991), (physical) safety (Folkman et al., 1986b), and 
Ridder, D. de, Kerssens, J. Owing to the force of circumstances? The impact of situational features and personal characteristics on coping patterns across situations. Psychology \& Health: 2003, 18(2), 217-236

competence (Folkman et al., 1986b; Mattlin et al., 1990). These concerns will be presented at a concrete surface level that can be recognized by most people (see Method section for details).

While concerns may be considered situational features that motivate coping responses, other features may affect the coping processes by the constraints they impose, either upon possible coping options or upon the employment of coping preferences. In this study, we analyze the impact of two such features: ambiguity and social context. Ambiguity refers to the degrees of freedom present in a situation and thus to the extent to which the situation imposes its meaning upon the individual, a characteristic that has also been addressed as 'situational power' (Hettema et al., 1986; Paterson and Neufeld, 1987). Unambiguous ('strong') situations are straightfor- ward and as such are unequivocal while ambiguous ('weak') situations allow for multiple interpretations. Social context of stressful situations is also known for the constraints it may impose on the coping process (Parkes, 1986). We discriminate between private situations characterized by informal relationships (e.g., family contexts) and public situations, which are characterized by formal relationships (e.g., work contexts) or by the presence of unknown people.

The objective of this study is to determine the extent to which situational features impact coping responses in dealing with stressful events. We assume that the explicit consideration of relevant situational characteristics (concerns, ambiguity, and social context), as well as the employment of a methodology that allows for the simultaneous assessment of situational characteristics and personal characteristics, will provide a more accurate picture of the way coping responses are influenced by situational features. The employment of a design with repeated measures in which individuals are exposed to similar (hypothetical) situations allows for analyzing variability in coping within individuals across situations. As no former research is available to formulate clear assumptions about the way situational features impact coping responses, our research is mainly of an exploratory nature. However, some general hypotheses may be stated. First, we hypothesize that variability in coping responses across situations is large and that such variability is accounted for by situational characteristics. Second, we hypothesize that, compared to ambiguity and social context, concerns at stake are the most important source of situational variability as they are the primary triggers of coping efforts. Third, with regard to the characteristics of ambiguity and social context, we hypothesize that both unambiguous and public social situations have a stronger impact on coping attempts than ambiguous and private situations respectively.

\section{METHOD}

\section{Participants and Procedure}

Participants were 430 adults (185 men and 245 women), aged 18-64 years (M 36 years, SD 12 years) who had agreed to participate in a study on 'the natural course of daily stress'. They were recruited by written invitation and telephoned within a week; addresses and telephone numbers were drawn from the files of the local telephone company. Persons were eligible for the study if they met the following criteria: age between 18 and 65 years, and being able to read and write in Dutch. Of the 597 persons who could be contacted, 430 (72\%) agreed to 
Ridder, D. de, Kerssens, J. Owing to the force of circumstances? The impact of situational features and personal characteristics on coping patterns across situations. Psychology \& Health: 2003, 18(2), 217-236

participate, 138 (23\%) refused for reasons of lack of time or lack of interest, and 29 (5\%) agreed but cancelled before the inter- view. A comparison of the characteristics of the sample with population characteristics (figures from the Municipal Health Service) learned that the sample was fairly representative according to criteria of marital status (44\% married) and employment status (67\% working), but that the participants of the study were somewhat younger and better educated (56\% of the sample had a college degree or a university degree in contrast to only $30 \%$ of the population).

An appointment was made for a home interview during which some personal characteristics were recorded and a series of vignettes on stressful situations were presented to assess the situation-specific elements of coping. All other measures were obtained by self-report questionnaires that were sent before the interview and collected after its completion.

\section{Design and Measures}

Situational characteristics were not assessed separately as they were included in written vignettes depicting daily hassles that were systematically varied according to the three situational features presented in the introduction: concern at stake (five categories: attachment, control, competence, (physical) safety, and predictability), ambiguity (two categories: ambiguous and unambiguous), and social context (two categories: private and public). Employing a facet design (Borg and Shye, 1995), we ensured that each situation represented a unique combination of the categories of the three dimensions (a $5 \times 2 \times 2$ design makes twenty situations). Facet design is especially useful for systematically disentangling the implicit 'facets' that constitute a complex concept such as 'stressful situation' (Dancer, 1990; Borg and Shye, 1995). A sample vignette is the following: "You have been suffering from a cold for a while. The last few days you have fits of dizziness and you feel exhausted."' This represents a situation in which physical safety is threatened in an ambiguous manner in a private context. The entire set of twenty vignettes (see Appendix for a complete listing) can be evaluated in three ways: by concern at stake (five concerns each represented by four vignettes), ambiguity (two categories each represented by ten vignettes), and social context (two categories each represented by ten vignettes). ${ }^{1} \mathrm{~A}$ validity check of the manipulated situational features in a pilot study (n $1 / 420)$ resulted in an average of $85 \%$ correct classification of these features as belonging to the relevant category. It appeared that it was more difficult to discriminate between concerns (especially between the concern of control and the concern of predictability that were confused in $28 \%$ of the cases) while discrimination between ambiguous and non ambiguous and between private and public situations was more easily obtained (89 and $91 \%$ correct classification respectively). Table I provides an overview of the three features that were manipulated in the vignettes.

In contrast to designs in which participants report about their idiosyncratic experience of stressful situations, the employment of vignettes warrants a similar exposure to the stressful features that were systematically manipulated in the depiction of daily hassles. The design may thus be regarded a quasi-experimental study, combining the advantages of a self-report method and an experimental method (cf. Coyne and Racioppo, 2000). A disadvantage of this approach lies in its potential artificiality that may weaken external validity when participants are not familiar with the stressful situations described in the vignettes, and thus may 
Ridder, D. de, Kerssens, J. Owing to the force of circumstances? The impact of situational features and personal characteristics on coping patterns across situations. Psychology \& Health: 2003, 18(2), 217-236

be tempted to make up coping responses. However, a number of studies have specified conditions in which responses to vignettes are valid, such as the opportunity to give vignettes careful and deliberate attention (Stolte, 1994; Barter and Renold, 2000). According to Krohne and Egloff (in press), vignettes as a valid method for eliciting coping responses when they meet the following two prerequisites. First, situations have to be sufficiently imaginable for respondents; which means that a considerable number of participants should have experienced similar stressors before. Imaginability is directly related to ecological validity, as vignettes that are too far removed from the everyday experience of the respondents do not guarantee valid answers. Second, vignettes have to induce a certain degree of threat in order to elicit coping efforts, although the experienced threat should not be too severe in order to allow for variability in coping responses. We took care that both prerequisites were met in the present study. First, it was warranted that the vignettes represented familiar daily hassles by asking participants whether they ever had experienced a similar situation, which was answered affirmatively by a vast majority of the participants for all situations depicted in the vignettes. Second, we checked whether the employed vignettes induced a reasonable amount of threat by asking for primary appraisal of the situation (see Results section for details).

\section{[TABLE 1]}

Situation-specific coping was measured by instructing participants to identify with the situation depicted in a particular vignette and subsequently sort coping items on a 5-point scale (ranging from 'not at all' to 'a great deal') presented on a board to facilitate imagination and concentration. As they had to repeat this procedure twenty times, the number of coping items had to be limited. Sixteen items were used, derived from the Ways of Coping Questionnaire (WCQ; Folkman and Lazarus, 1988), representing eight coping scales by the two most typical items (with the highest factor loadings) on that particular scale: planful problem solving, distancing, seeking social support, self- control, escape/avoidance, positive reappraisal, accepting responsibility, and confrontation. Although this procedure does not allow for a regular reliability check of the scales, a similar strategy has been employed regularly in the repeated measurement of coping (Stone and Neale, 1984; Porter and Stone, 1996; Peters et al., 2000). Scales with a low number of items or even one-item scales are considered valid when they refer to the typical content of the particular concept (Burisch, 1984) and aim to assess state measures (Porter and Stone, 1996). In order to prevent social desirable answers, it was emphasized that it did not matter whether respondents were consistent or variable in answering coping items for each of the situations. In addition to the report on the use of the particular coping behaviors in each situation, participants indicated whether they thought the situation allowed for free choice between coping strategies in a dichoto- mous format (yes or no) (cf. Ben-Porath et al., 1991; Stone et al., 1991). Also, they answered two one-item questions concerning the stressful nature of the depicted situations as a proxy for primary appraisal ('Do you feel threatened by this situation?' on a 5-point scale, varying from 'not at all' to 'a great deal') and their ability to deal with it as a proxy for secondary appraisal ('Do you experience any difficulty to deal with this situation?' on a 5point scale, varying from 'not at all' to 'a great deal'). 
Ridder, D. de, Kerssens, J. Owing to the force of circumstances? The impact of situational features and personal characteristics on coping patterns across situations. Psychology \& Health: 2003, 18(2), 217-236

Finally, personal characteristics were administered (by questionnaire) to assess the impact of personal coping resources on coping. The following resources were selected because of their relevance for coping (cf. Hobfoll, 2001): (1) General Health Questionnaire-28 (28 dichotomous items with anchors 'no' and 'yes'; Cronbach's alpha 0.92; Goldberg, 1972) as an indication of mental health; (2) Selfesteem (10 items measured on a 4-point scale, varying from 'not at all' to 'a great deal'; Cronbach's alpha 0.84; Rosenberg, 1965); and (3) a Dutch measure for perceived social support (31 items measured on a 4-point scale, varying from 'not at all' to 'a great deal'; Cronbach's alpha 0.96; Van Sonderen, 1991). In addition, subjects completed an adapted version of the WCQ (67 items on a 6-point scale, varying from 'not at all' to 'a great deal'; Folkman and Lazarus, 1988) with the instruction to indicate their habitual coping styles generalizing across the particular demands of situations (Van Heck and Vingerhoets, 1989). A factor analysis (eigenvalue $>1$ ) yielded seven coping styles: planful problem solving (14 items, Cronbach's alpha 0.81), accepting responsibil- ity (10 items, Cronbach’s alpha 0.81), escape/avoidance (8 items, Cronbach's alpha 0.77), positive reappraisal (8 items, Cronbach's alpha 0.76 ), distancing (7 items, Cronbach's alpha 0.72), wishful thinking ( 3 items, Cronbach's alpha 0.82), and confrontation (2 items, Cronbach's alpha 0.47). Although the WCQ is notorious for its unstable factor solutions across different samples (cf. Stone et al., 1991), these scales correspond fairly well with the original WCQ scales. Compared to the original WCQ, the present analysis shows one coping style (wishful thinking) that is not present in the WCQ, while two of the original WCQ styles (self-control and seeking social support) are absent. Remarkably, social support items do not constitute one scale but are present in several coping styles, which corresponds with studies showing that the global category of seeking support may take different forms, varying from seeking advice to expressing emotions (cf. Carver et al., 1989).

\section{Statistical Analysis}

All 430 participants reported for each of twenty situations the use of eight coping behaviors. These behaviors are dependent variables in a series of statistical analyses. To investigate the situational and personal impact on coping behaviors, situations were nested hierarchically under subjects. Then, by means of analysis of variance, total variance in coping behaviors was divided in between-individual variance $\left(\mathrm{a}^{2}{ }_{\text {ind }}\right)$, indicating the variation between 430 subjects, and pooled-within variance $\left(\mathrm{a}^{2}{ }_{\text {sit }}\right)$, relating to the variation in situations within individuals. The intraclass coefficient $\mathrm{p}$ is defined as $\left(\mathrm{a}^{2}{ }_{\text {ind }} /\left(\mathrm{a}^{2}{ }_{\text {sit }} \mathbf{p} \mathrm{a}^{2}{ }_{\text {ind }}\right)\right)$. When $\mathrm{a}^{2}$ ind is close to zero, $\mathrm{p}$ is also close to zero. In that case, variance between individuals is absent and all variation is between situations - indicating large situational impact. When $\mathrm{a}^{2}$ sit is close to zero, $\mathrm{p}$ is close is close to zero, $\mathrm{p}$ is close to unity. In that case, variation between situations is small while there are relatively large differences between individuals; and thus the personal impact is considered to be large. In other words, $\mathrm{p}$ is a measure of personal impact in relation to the situational impact on coping behaviors. In contrast to traditional forms of analysis of variance in which factors have 'fixed' effects, both subjects and situations are considered to have 'random' effects. Such a variance component model (Searle et al., 1992) is preferred over traditional analysis of variance if a factor is randomly sampled (in this case: subjects) or if the number of categories exceeds ten (in this study: both 
Ridder, D. de, Kerssens, J. Owing to the force of circumstances? The impact of situational features and personal characteristics on coping patterns across situations. Psychology \& Health: 2003, 18(2), 217-236

subjects and situations) (Snijders and Bosker, 1999). Eight variance component models were analyzed, one for each coping behavior.

Dividing variance into a personal and a situational component is the first step in statistical analyses. Explaining these variance components by situational features and personal variables is the second step. Because of the nesting of situations under subjects, data on two levels are available (cf., Hox et al., 1991). The study design may thus be considered a two-stage sample, the first stage being a random sample of subjects, the second being a sample of situations; implying that there are 8600 ( $430 \times 20)$ observations for each type of coping behavior. These observations cannot be considered independent, because coping behaviors of one subject across different situations will be more alike than coping behaviors of different subjects. ${ }^{2}$ To correct for dependency of observations, a special form of linear regression analysis, multilevel (or hierarchical linear) modeling (Bryk and Raudenbusch, 1992; Goldstein, 1995) was applied. The multilevel model takes into account the dependencies that are present in the data and adjusts the standard errors of the estimated coefficients accordingly. To facilitate interpretation, all variables were tranformed to z-scores, so that regression coefficients become correlation coefficients (Kerlinger and Pedhazur, 1973). After standardization, a series of models were computed with each coping behavior as a dependent variable.

Hierarchical linear models specified in this way are named 'oneway ANCOVA with random effects' models (Bryk and Raudenbusch, 1992). Before data were analyzed in this way, using ML3 software (Rashbash and Woodhouse, 1995), a number of validity checks on the data were performed.

\section{RESULTS}

Table II provides a description of some elementary features of coping across situations. First, taking into account that the situations depicted in the vignettes belong to the category of daily hassles, figures on primary appraisal (in the top row of Table II) show that the twenty situations were considered rather threatening ( $\mathrm{M}$ 3.3 on a 5-point scale with higher figures indicating more threat). Participants experienced some difficulty in dealing with these situations, indicated by the figures on secondary appraisal (M 3.4 on a 5-point scale with higher figures indicating more difficulty).

Apparently, participants feel challenged but not overwhelmed by the situations. We may conclude that the situations depicted in the vignettes make an appeal and thus may be considered valid triggers of coping responses.

Table II also provides figures on the associations between appraisals and coping strategies. As discussed in the introduction, a number of studies have demonstrated a significant association between appraisals and coping responses (Folkman and Lazarus, 1980; Forsythe and Compas, 1987). Our findings, presented in the right hand column of Table II, point in the same direction and show that higher appraisals of threat (primary appraisal) are associated with evaluations of more difficulty to deal with the situation (secondary appraisal) and with the increased effort of almost all strategies except escape/avoidance and accepting responsibility that appear rather immune for perceptions of threat. The extent to which one considers oneself able to deal with the situation (secondary appraisal), in contrast, is overall less strongly related to the employment of strategies with the exception of confrontation and distancing. It appears that in the anticipation 
Ridder, D. de, Kerssens, J. Owing to the force of circumstances? The impact of situational features and personal characteristics on coping patterns across situations. Psychology \& Health: 2003, 18(2), 217-236

of difficulty to deal with the situation, more coping efforts are spent on the strategies that come nearest to basic fight-flight reactions. Overall, associations between appraisals and coping demonstrate that appraisals are important but not determining factors in shaping coping responses.

\section{[TABLE 2]}

A third feature of coping is described in the left hand column of Table II and shows participants' ratings of the applicability of coping, indicated by the percentage of persons who responded affirmatively to the question whether a particular coping response was applicable in a situation (in Table II, the average applicability over twenty situations is reported for each strategy). An important issue regarding situation-specific coping is whether all strategies have the same a priori chance to be used in particular situations. In an analysis of the applicability of WCQ strategies, Stone (Stone et al., 1991) reported that an average of $83 \%$ of the items was considered applicable in various situations. Our findings show that participants are somewhat more positive and rate that strategies were applicable in about $90 \%$ of the situations presented to them. Confrontation and accepting responsibility are considered somewhat less applicable (85 and 86\% respectively) while self-control and distancing are considered the most widely applicable (95 and $97 \%$ respectively). As participants were instructed to rate applicability after having reported whether they would use the strategy in the given situation, evaluation of applicability is not contaminated by evaluation of personal ability to deal with the situation (which would be more like a secondary appraisal) or about what they considered appropriate (which would reflect social norms about applicability). Finally, Table II gives a provisional idea of the variability of coping across situations indicated by the employment of each strategy, averaged over twenty situations. These figures show that, at a general level, all strategies were employed to a reasonable extent.

Another issue relates to the personal resources participants may utilize in dealing with stressful situations. Table III indicates high availability of those resources as most participants report good mental health (M 5.3 on the GHQ-28 which is far below the threshold of 11 - indicating risk of mental health conditions), high amounts of perceived support (M 3.2 on a 4-point scale), and high self-esteem (M 3.1 on a 4-point scale). Table III also shows that planful problem solving, distancing, and accepting responsibility generally are the most preferred coping styles while escape/ avoidance and wishful thinking are preferred the least.

\section{[TABLE 3 AND TABLE 4]]}

We now turn to the main issue of this study and analyze the relative impact of situational and personal influences on coping. To that purpose, we first conducted eight analyses of variance components over 8600 ( 430 x 20) situations. Table IV shows that averaged over 8600 situations the most applied strategies are accepting responsibility, confrontation, and seeking social support while escape/avoidance is the least employed strategy. Table IV also shows the total variance in each coping strategy as well as the variance of its two constituting components, namely the variance between persons (labeled person variance) and the variance between situations within persons (labeled situational variance 'pooled within'). For each strategy, the variance between situations within persons is larger than the variance 
Ridder, D. de, Kerssens, J. Owing to the force of circumstances? The impact of situational features and personal characteristics on coping patterns across situations. Psychology \& Health: 2003, 18(2), 217-236

between persons, meaning that persons vary more in their coping reactions across situations than they vary as individuals compared with each other. This phenomenon is also shown by the intraclass coefficient $\mathrm{p}$ that represents the relation between both variance components. The largest intraclass coefficient is reported for self-control, indicating a strategy that is applied relatively most independently of situational constraints; the lowest intraclass coefficient is reported for the strategy of planful problem solving, that is thus the most situation-dependent strategy. The six other strategies are in between these extremes - confrontation, positive reappraisal, and distancing being relatively more depending on personal factors $(\mathrm{p}>0.20)$ and escape/avoidance, seeking social support, and accepting responsibility being relatively more depending on situational factors $(\mathrm{p}<0.15)$.

Knowing that there is considerable variability within persons across situations, the next step is to identify which situational features and personal factors are responsible for the established pattern of coping. To that purpose, we conducted a series of multi- level analyses. Table $\mathrm{V}$ gives an overview of the standardized regression coefficients $b$ and shows that all three situational features (ambiguity, social context, and concern at stake) have a significant impact on almost all coping strategies. The presented b's refer to the category indicated in Table V compared with their reference (e.g., b's reported on the feature of ambiguity refer to unambiguous situations compared with ambiguous situations; b's reported on each of the concerns are compared with the refer- ence of competence situations). The extent to which a situation imposes its meaning upon individuals is apparently a relevant feature as the employment of all strategies is related to the ambiguity of the situation: unambiguous situations lead to increased coping efforts for all strategies except social support, that is employed significantly less in these situations. Applying the criterium of $b>|0.20|$ for moderate effects, especially planful problem solving is used at a higher frequency in unambiguous situations. It appears that strong situations do not so much elicit particular strategies but lead to increased effort in general when compared with ambiguous situations. The feature of social context is also a relevant characteristic with private situations tending to generate more efforts of almost any kind, although strong effects are absent. The only strategies that are less employed in private situations are planful problem solving and, to a lesser extent, distancing. Both strategies are more often employed in public situations.

\section{[TABLE 5]}

Concern at stake is also an important factor in shaping coping behavior as different concerns elicit different coping responses. Compared with the reference of competence situations, situations that threaten the concern of attachment lead to increased problem solving and distancing responses, and decreased escape/avoidance. When predictability is at stake, participants tend to use fewer strategies than in competence situations (especially less escape/avoidance and less taking responsibility) and they employ slightly more problem solving and support seeking responses. When safety is at stake, no clear pattern can be distinguished, although confrontation and self-control are used somewhat more and accepting responsibility and problem solving are used considerably less, compared to situations in which competence is threatened. Safety situations thus appear to call 
Ridder, D. de, Kerssens, J. Owing to the force of circumstances? The impact of situational features and personal characteristics on coping patterns across situations. Psychology \& Health: 2003, 18(2), 217-236

for decreased problem-focused coping. When control is at stake, participants are inclined to approach the situation by employing more problem solving efforts and significantly less escape/avoidance or positive reappraisal. Compared to competence situations, control situations clearly call for action. The three features thus demonstrate a considerable role for situational impacts on coping. Having established the impact of situational features on coping, the role of personal factors needs to be assessed. Socio-demographic characteristics like sex, age, and education are barely relevant, with only very few significant effects. Remarkably, the impact of personal resources such as good mental health, the availability of social support, and high self-esteem on coping is also limited, and the same holds for the impact of coping styles: in most cases, significant effects are absent or weak $(b<|0.15|)$. However, even though no typical personal variables can be identified as important factors in the coping process, their joint effect explains a considerable amount of variance at the personal level (indicated in the bottom row of Table V).

The bottom row of Table $\mathrm{V}$ shows that variance at the personal level can be better explained by personal factors than the variance at the situational level can be explained by situational factors. Only 2-26\% (average: $10 \%$ ) of the variance at the situational level is explained by the three situational features that were employed in this study while 6-28\% (average: 16\%) of the variance at the personal level is explained by the combined impact of sociodemographic characteristics, personal resources, and coping styles. Thus, although the variability between persons is lower than the variability across situations, variance at the personal level is in most cases better explained by the personal variables included in the model. ${ }^{3}$ This holds especially for the strategies of distancing (28\% variance explained by personal variables) and escape/avoidance (26\% variance explained by personal variables).

\section{DISCUSSION}

Although research on situation-specific coping has called for much debate in the past decades, few efforts have been spent on clarifying the nature of situational impacts on coping. In this study, we made an attempt to assess the impact of situational features that are both theoretically relevant and can be assessed independently of subjective appraisal. We established that variability within persons across situations is considerably larger than variability between persons who are dealing with the same event. Large situational variability holds especially for the strategies of planful problem solving, escape/avoidance, social support seeking, and accepting responsibility while self-control, confrontation, distancing, and positive reappraisal are less variable across situations. Even less variable strategies, however, are still employed with relative variability across situations as figures on the variance components have demonstrated. These findings partly correspond with the findings of Folkman (Folkman et al., 1986b), who reported the lowest mean autocorrelations (averaged over five occasions) for planful problem solving, social support seeking and confrontation - thus indicating high variability - and the highest for self-control, positive reappraisal, and escape/ avoidance - thereby indicating low variability. While it is difficult to determine to what extent our figures represent variability across situations in an absolute sense, it is clear that people do take account of 
Ridder, D. de, Kerssens, J. Owing to the force of circumstances? The impact of situational features and personal characteristics on coping patterns across situations. Psychology \& Health: 2003, 18(2), 217-236

situational constraints in their coping responses. In this study, we accounted for three situational demands and our analyses demonstrate the relevance of all of them. Ambiguity, social context, and concern at stake all proved significant in shaping coping responses. Ambiguity has the most straightforward impact: when a situation is unequivocal people are inclined to invest more coping efforts while ambiguous situations call for a wait-and-see strategy characterized by decreased effort of any coping response. In a sense, the pattern of coping with regard to ambiguity resembles the basic approach-avoidance distinction: people either engage with the situation by increased problem-solving efforts (in case of unambiguity) or disengage from the situation by detaching themselves (in case of ambiguity).

The impact of social context on the coping process is somewhat less clear. Generally, private situations call for more coping than public ones but none of the strategies were prominent with the clear exception of problem-solving that was used considerably less in private situations. It may be that people are more inclined to employ emotion- focused coping (i.e., other than problem solving efforts) in private situations because these situations make a greater appeal although our analyses do not indicate increased threat in private situations. The greater use of problem solving in public contexts may also reflect social norms about rational responses that may be more manifest in situations in which colleagues are present or which are otherwise of a public nature (cf. Weber, 2000). Concern at stake is a situational feature that we considered to be 'objectively' present in the vignettes. In this capacity, all concerns appear to have a strong impact on coping behavior. When control was at stake, an action pattern was distinguished, characterized by increased problem solving efforts and decreased escape/avoidance and positive reappraisal (taking situations that threaten competence as a reference). When predict- ability was at stake, decreased accepting responsibility and decreased escape/avoidance were observed, suggesting a pattern of monitoring the situation without immediate attempts to deal actively with it. It may be that in unpredictable situations people tend to stay tuned to the situation and wait and see how it develops. When safety was at stake, a pattern of fewer problem solving attempts and less accepting responsibility was observed - suggesting decreased problem-focused coping which may be an indication that threats to safety leave few options to deal actively with the situation. Threats to attachment resulted in a remarkable pattern of more problem solving and distancing and decreased escape/avoidance, which may be interpreted as a strategy of alternate awareness that one should do something about the situation and attempts to disengage from the situation (cf. Folkman et al., 1986a who found a similar alternating pattern when a loved one's well being was at stake).

Generally, our findings on the role of concerns in the coping process corroborate the findings of Folkman and colleagues (1986a), who established a significant relationship between types of concerns and coping responses.

We assumed that the three situational features would have a differential impact on coping as concerns are considered to motivate coping by creating actionpreparedness while ambiguity and social context would limit the range of options that can be applied in a particular situation. Although the design does not allow for a strict test of this assumption, our data suggest a pattern in which the role of ambiguity and social context is somewhat more outspoken in a sense that these 
Ridder, D. de, Kerssens, J. Owing to the force of circumstances? The impact of situational features and personal characteristics on coping patterns across situations. Psychology \& Health: 2003, 18(2), 217-236

features promote some strategies and inhibit others while the role of concerns indicates a more qualitative impact on coping, suggesting differentiated patterns depending on the type of concern. As stated earlier, variance in coping at the personal level is smaller than the variance at the situational level, but remarkably, this variance can be explained rather well by the personal factors included in the study, although none of these factors appeared very important by itself. These findings contradict claims about the assumed relevance of perceived social support and other personal resources that are often regarded as relevant determinants of coping (Lazarus and Folkman, 1984). These findings may be attributed to the homogeneity of the sample, as most subjects reported to be rather well provided with these resources. An alternative interpretation is that the absence of single significant factors suggests the presence of a latent resilience factor that is reflected by the joint influence of all the resource variables. Further research should clarify the role of personal resources in shaping the coping process.

A striking finding is the absence of an association between dispositional coping styles and the employment of related coping strategies in particular situations - a finding that has also been reported in other studies (Carver and Scheier, 1994; Schwartz et al., 1999). In our study, the value of this result is limited by the absence of concordance between situational and dispositional coping measures when employing standard psychometric scaling procedures for the latter. However, one would expect a more distinctive role for dispositional coping even in case of imperfect correspondence with situational coping. At this point, it is unclear whether this finding illustrates the modest role of coping dispositions in shaping actual responses or whether it refers to the poor measurement of the concept of coping styles. Our findings also downplay the role of personal characteristics such as sex and education that have often been reported as relevant determinants of coping (Ptacek and Dodge, 1994; De Ridder, 1995). However, contradictory findings regarding these factors have also been reported and the debate about conceptualizing their impact is continuing. To the extent that we have been able to incorporate relevant personal resources in our study, our findings demonstrate that their joint influence on coping is modest and cannot be attributed to single factors. The significance of our findings is limited to the extent that the coping strategies measured by the WCQ represent a valid and reliable categorization of coping responses. In the past years, increasing criticism has been uttered on the representativeness of the WCQ scales and related measures (Coyne and Gottlieb, 1996; De Ridder, 1997). Also, difficulties associated with replicating the scale structure in different samples have been a reason for repeated critical comments (cf., Stone et al., 1991). However, it must also be noted that, in spite of all critical remarks, consensus on the number and quality of coping strategies beyond the level of metastrategies (i.e., problem-focused versus emotion-focused or approach-avoidance) is still lacking (Coyne and Racioppo, 2000). For that reason, at present no clear alternative categorization of coping behavior is available if the focus is on measuring coping responses that are more detailed than meta-strategies. The value of our findings is also related to the representativeness of the situational features that were included in this study. Few studies are available to inform a rational selection of relevant situational features that meet the criteria 
Ridder, D. de, Kerssens, J. Owing to the force of circumstances? The impact of situational features and personal characteristics on coping patterns across situations. Psychology \& Health: 2003, 18(2), 217-236

that were applied in this study (i.e., psychologically relevant and measurable beyond subjective appraisal). To the best of our knowledge, we made a selection of features that have been reported in the scarce studies highlighting the relevance of a situational taxonomy for psychological research. However, this study only has taken into account three such features while there may be more. Situational features were manipulated in vignettes depicting hypothetical situations. Asking respondents to imagine the same fictitious situations has the obvious advantage that they have more or less the same situation in mind while endorsing coping items. However, it may be that hypothetical situations do not provide an accurate account of what people would do when actually confronted with these situations and thus make up coping responses or provide socially desirable answers. No studies are available that examine to what extent responses to vignettes are associated with responses to real life stressors. However, one could raise a similar argument against the use of self-report coping questionnaires that may be biased by retrospective self-report about 'real' stressors. To reduce the possibility of unvalid responses to imaginative stressors, we made sure that our vignettes were ecologically valid by including vignettes that were familiar to participants from everyday experience. Our study has exemplified the role of situational features as relevant determinants of coping responses in stressful situations. We feel that this approach is a valuable complement to coping research that has been dominated by an approach in which adaptive behavior is exclusively viewed as the expression of dispositional coping styles and has taken for granted that situational demands may constraint coping preferences. Researching explicitly the role of situations may be helpful in solving the current crisis in coping research (Somerfield and McCrae, 2000), as it provides more insight in the triggers of adaptive attempts and also suggests ways of developing coping measures that are tailored to the demands of specific stressors. The latter approach has been advocated as a promising way out of the crisis but bears the risk of inductively developing multiple coping scales that may be relevant for describing coping with specific stressors (e.g., bereavement or chronic pain), but cannot be understood at a more abstract level. Therefore, research on the way situational features constraint coping responses may be helpful in developing such situation-specific scales.

\section{ACKNOWLEDGEMENTS}

The authors wish to thank Paul Leseman for his essential advice on the design of the study and Mieke te Vaarwerk for her help in data-collection and preliminary data-analysis.

\section{REFERENCES}

Aldwin, C.M. and Stokols, D. (1988). The effects of environmental change on individuals and groups: some neglected issues in stress research. Journal of Environmental Psychology, 8, 57-75.

Barter, C. and Renold, E. (2000). 'I wanna tell you a story': exploring the application of vignettes in qualita- tive research with children and young people. International Journal of Social Research Methodology: Theory and Practice, 3, 307-323.

Ben-Porath, Y.S., Waller, N.G. and Butcher, J.N. (1991). Assesment of coping: an empirical illustration of the problem of inapplicable items. Journal of Personality Assessment, 57, 162-176. 
Ridder, D. de, Kerssens, J. Owing to the force of circumstances? The impact of situational features and personal characteristics on coping patterns across situations. Psychology \& Health: 2003, 18(2), 217-236

Bensing, J.M., Schreurs, K.M.G., De Ridder, D.T.D. and Hulsman, R.L. (2002). Adaptive tasks in multiple sclerosis: development of an instrument to identify the focus of patients coping efforts. Psychology and Health, 17, 475-488.

Borg, I. and Shye, S. (1995). Facet Theory: Form and Content. Sage, Thousand Oaks, CA.

Bryk, A.S. and Raudenbusch, S.W. (1992). Hierarchical Linear Models: Applications and Data Management Methods. Sage, Newbury Park.

Burisch, M. (1984). Approaches to personality inventory construction: a comparison of merits. American Psychologist, 39, 214-227.

Carver, C.S. and Scheier, M.F. (1994). Situational coping and coping dispositions in a stressful transaction.

Journal of Personality and Social Psychology, 66, 184-195.

Carver, C.S., Scheier, M.F. and Weintraub, J.K. (1989). Assessing coping strategies: a theoretically based approach. Journal of Personality and Social Psychology, 56, 267283.

Cheng, C. (2001). Assessing coping flexibility in real-life and laboratory settings: a multimethod approach.

Journal of Personality and Social Psychology, 80, 814-833.

Cheng, C., Hui, W. and Lam, S. (1999). Coping style of individuals with functional dyspepsia. Psychosomatic Medicine, 61, 789-795.

Cochrane, W.G. (1977). Sampling Techniques. Wiley, New York.

Coyne, J.C. and Gottlieb, B.H. (1996). The mismeasure of coping by checklist. Journal of Personality, 64, 959-991.

Coyne, J.C. and Racioppo, M.W. (2000). Never the twain shall meet? Closing the gap between coping research and clinical intervention research. American Psychologist, 55, 855-664.

Dancer, L.S. (1990). Introduction to facet theory and its applications. Applied Psychology: An International Review, 39, 365-377.

De Ridder, D.T.D. (1995). Social status and coping: an exploration of the mediating role of beliefs. Anxiety, Stress, and Coping, 8, 311-324.

De Ridder, D.T.D. (1997). What is wrong with coping assessment? A review of conceptual and methodolo- gical issues. Psychology and Health, 12, 417-431.

Dunkel-Schetter, C., Feinstein, L.G., Taylor, S.E. and Falke, R.L. (1992). Patterns of coping with cancer.

Health Psychology, 11, 79-87.

Endler, N.S. and Parker, J.D.A. (1990). Multidimensional assessment of coping: a critical evaluation. Journal of Personality and Social Psychology, 58, 844-854.

Folkman, S. (1984). Personal control and stress and coping processes: a theoretical analysis. Journal of Personality and Social Psychology, 46, 839-852.

Folkman, S. and Lazarus, R. (1980). An analysis of coping in a middle-aged community sample. Journal of Health and Social Behavior, 21, 219-239.

Folkman, S. and Lazarus, R. (1985). If it changes it must be a process: a study of emotion and coping during three stages of a college examination. Journal of Personality and Social Psychology, 48, 150-170.

Folkman, S. and Lazarus, R.S. (1988). The Ways of Coping Questionnaire. Consulting Psychologists Press, Palo Alto, CA.

Folkman, S., Lazarus, R., Dunkel-Schetter, C., DeLongis, A. and Gruen, R. (1986a). Dynamics of a stressful encounter: cognitive appraisal, coping, and encounter outcomes. Journal of Personality and Social Psychology, 50, 992-1003.

Folkman, S., Lazarus, R., Gruen and DeLongis, A. (1986b). Appraisal, coping, health status, and psycholo- gical symptoms. Journal of Personality and Social Psychology, 50, 571-579.

Forsythe, C.J. and Compas, B.E. (1987). Interaction of cognitive appraisals of stressful events and coping: testing the goodness-of-fit hypothesis. Cognitive Therapy and Research, 11, 473-485. Frijda, N (1986). The Emotions. Cambridge University Press, Cambridge.

Goldberg, D. (1972). Manual of the General Health Questionnaire. NFER Publishing, Windsor. Goldstein, H. (1995). Multilevel Statistical Models. Halsted, New York. 
Ridder, D. de, Kerssens, J. Owing to the force of circumstances? The impact of situational features and personal characteristics on coping patterns across situations. Psychology \& Health: 2003, 18(2), 217-236

Hettema, J., Van Heck, G.L., Appels, M. and Van Zon, I. (1986). The assessment of situational power.

In: Angleitner, A., Furnham, A. and VanHeck, G.L. (Eds.), Personality Psychology in Europe. Vol. II. Current Trends and Controversies. Swets \& Zeitlinger, Lisse.

Hobfoll, S.E. (2001). The influence of culture, community, and the nested-self in the stress process: advancing conservation of resources theory. Applied Psychology: An International Review, 50, 337-370.

Hox, J.J., Kreft, I.G.G. and Hermkens, P.L.J. (1991). The analysis of factorial surveys. Sociological Methods and Research, 19, 493-510.

Kerlinger, F.N. and Pedhazur, E.J. (1973). Multiple Regression in Behavioral Research. Holt, Rinehart \& Winston, New York.

Krohne, H.W. and Egloff, B. (in press). Vigilant and avoidant coping. Theory and measurement. In: Spielberger, C.D. and Sarason, I.G. (Eds.), Stress and Emotion, Vol. 7. Taylor \& Francis, Washington, DC.

Lazarus, R.S. (1991). Emotion and Adaptation. Oxford University Press, New York. Lazarus, R.S. and Folkman, S. (1984). Stress, Appraisal, and Coping. Springer, New York.

Lester, N., Smart, L. and Baum, A. (1994). Measuring coping flexibility. Psychology and Health, 9, 409-424. McCrae, R.R. (1984). Situational determinants of coping responses: loss, threat, and challenge. Journal of Personality and Social Psychology, 46, 919-928.

Mattlin, J.A., Wethington, E. and Kessler, R.C. (1990). Situational determinants of coping and coping effectiveness. Journal of Health and Social Behavior, 31, 103-122.

Neufeld, R.W.J. (1999). Dynamic differentials of stress and coping. Psychological Review, 106, 385-397. Parkes, K.R. (1986). Coping in stressful episodes: the role of individual differences, environmental factors, and situational characteristics. Journal of Personality and Social Psychology, 51, 1277-1292 Paterson, R.J. and Neufeld, W.J. (1987). Clear danger: situational determinants of the appraisal of threat.

Psychological Bulletin, 101, 404-416.

Peters, M.L., Sorbi, M.J., Kruisse, D.A., Kerssens, J.J., Verhaak, P.F.M. and Bensing, J.M. (2000). Electronic diary assessment of pain, disability and psychological adaptation in patients differing in duration of pain. Pain, 84, 181-192.

Porter, L.S. and Stone, A.A. (1996). An approach to assessing daily coping. In: Zeidner, M. and Endler, N.S. (Eds.), Handbook of Coping: Theory, Research, Applications, pp. 133-150. Wiley, New York.

Ptacek, J.T. and Dodge, K.L. (1994). Gender differences in coping with stress: when stressor and appraisals do not differ. Personality and Social Psychology Bulletin, 20, 421-430.

Rasbash, J. and Woodhouse, G. (1995). MLN Command Reference. Institute of Education, University of London, London.

Rosenberg, M. (1965). The Measurement of Self-esteem. Society and the Adolescent Self-image. Princeton University Press, Princeton.

Schwartz, C.E., Peng, C.K., Lester, N., Daltroy, L and Goldberger, A. (1998). Coping behavior in health and disease: assessment with a card sort game. Behavioral Medicine, 24, 41-44.

Schwartz, J.E., Neale, J., Marco, C., Shiffman, S.S. and Stone, A.A. (1999). Does trait coping exist? A momentary assessment approach to the evaluation of traits. Journal of Personality and Social Psychology, 77, 360-369.

Searle, S.R., Casella, G. and McGullogh, C.E. (1992). Variance Components. Wiley, New York.

Snijders, T.A.B. and Bosker, R.J. (1999). Multilevel Analysis: An Introduction to Basic and Advanced Multilevel Modelling. Sage, London.

Somerfield, M.R. and McCrae, R.R. (2000). Stress and coping research. Methodological challenges, theor- etical advances, and clinical applications. American Psychologist, 55, $620-625$.

Stewart, S.M. and Schwarzer, R. (1996). Stability of coping in Hong Kong medical students: a longitudinal study. Personality and Individual Differences, 20, 245-255. 
Ridder, D. de, Kerssens, J. Owing to the force of circumstances? The impact of situational features and personal characteristics on coping patterns across situations. Psychology \& Health: 2003, 18(2), 217-236

Stolte, J.F. (1994). The context of satisficing in vignette research. Journal of Social Psychology, 134, 727-733.

Stone, A.A., Greenberg, M.A., Kennedy-Moore, E. and Newman, M.G. (1991). Selfreport, situation-specific coping questionnaires: what are they measuring? Journal of Personality and Social Psychology, 61, 648-658.

Stone, A.A. and Neale, J.M. (1984). A new measure of daily coping. development and preliminary results.

Journal of Personality and Social Psychology, 46, 892-906.

Tennen, H., Affleck, G., Armeli, S. and Carney, M.A. (2000). A daily process approach to coping. Linking theory, research, and practice. American Psychologist, 55, 626-636.

Van Heck, G.L. and Vingerhoets, A.J.J.M. (1989). Copingstijlen en persoonlijkheidskenmerken [Coping styles and personality characteristics]. Nederlands Tijdschrift voor de Psychologie, 44, 73-87.

Van Sonderen, E. (1991). Het meten van sociale steun [Measuring social support]. Ph.D. Thesis. University of Groningen, Groningen, The Netherlands.

Vitaliano, P.P., DeWolfe, D.J., Maiuro, R.D., Russo, J. and Katon, W. (1990). Appraised changeability of a stressor as a modifier of the relationship between coping and depression: a test of the hypothesis of fit.

Journal of Personality and Social Psychology, 59, 582-592.

Weber, H. (2000). Breaking all the Rules: Impact of Social Norms on Coping. Paper presented at the 14th Conference of the European Health Psychology Society, 16-19 August 2000. Leiden, The Netherlands.

Hox, J.J., Kreft, I.G.G. and Hermkens, P.L.J. (1991). The analysis of factorial surveys. Sociological Methods and Research, 19, 493-510.

Kerlinger, F.N. and Pedhazur, E.J. (1973). Multiple Regression in Behavioral Research. Holt, Rinehart \& Winston, New York.

Krohne, H.W. and Egloff, B. (in press). Vigilant and avoidant coping. Theory and measurement. In: Spielberger, C.D. and Sarason, I.G. (Eds.), Stress and Emotion, Vol. 7. Taylor \& Francis, Washington, DC.

Lazarus, R.S. (1991). Emotion and Adaptation. Oxford University Press, New York. Lazarus, R.S. and Folkman, S. (1984). Stress, Appraisal, and Coping. Springer, New York.

Lester, N., Smart, L. and Baum, A. (1994). Measuring coping flexibility. Psychology and Health, 9, 409-424. McCrae, R.R. (1984). Situational determinants of coping responses: loss, threat, and challenge. Journal of Personality and Social Psychology, 46, 919-928.

Mattlin, J.A., Wethington, E. and Kessler, R.C. (1990). Situational determinants of coping and coping effectiveness. Journal of Health and Social Behavior, 31, 103-122.

Neufeld, R.W.J. (1999). Dynamic differentials of stress and coping. Psychological Review, 106, 385-397. Parkes, K.R. (1986). Coping in stressful episodes: the role of individual differences, environmental factors, and situational characteristics. Journal of Personality and Social Psychology, 51, 1277-1292 Paterson, R.J. and Neufeld, W.J. (1987). Clear danger: situational determinants of the appraisal of threat.

Psychological Bulletin, 101, 404-416.

Peters, M.L., Sorbi, M.J., Kruisse, D.A., Kerssens, J.J., Verhaak, P.F.M. and Bensing, J.M. (2000). Electronic diary assessment of pain, disability and psychological adaptation in patients differing in duration of pain. Pain, 84, 181-192.

Porter, L.S. and Stone, A.A. (1996). An approach to assessing daily coping. In: Zeidner, M. and Endler, N.S. (Eds.), Handbook of Coping: Theory, Research, Applications, pp. 133-150. Wiley, New York.

Ptacek, J.T. and Dodge, K.L. (1994). Gender differences in coping with stress: when stressor and appraisals do not differ. Personality and Social Psychology Bulletin, 20, 421-430.

Rasbash, J. and Woodhouse, G. (1995). MLN Command Reference. Institute of Education, University of London, London.

Rosenberg, M. (1965). The Measurement of Self-esteem. Society and the Adolescent Self-image. Princeton University Press, Princeton. 
Ridder, D. de, Kerssens, J. Owing to the force of circumstances? The impact of situational features and personal characteristics on coping patterns across situations. Psychology \& Health: 2003, 18(2), 217-236

Schwartz, C.E., Peng, C.K., Lester, N., Daltroy, L and Goldberger, A. (1998). Coping behavior in health and disease: assessment with a card sort game. Behavioral Medicine, 24, 41-44.

Schwartz, J.E., Neale, J., Marco, C., Shiffman, S.S. and Stone, A.A. (1999). Does trait coping exist? A momentary assessment approach to the evaluation of traits. Journal of Personality and Social Psychology, 77, 360-369.

Searle, S.R., Casella, G. and McGullogh, C.E. (1992). Variance Components. Wiley, New York.

Snijders, T.A.B. and Bosker, R.J. (1999). Multilevel Analysis: An Introduction to Basic and Advanced Multilevel Modelling. Sage, London.

Somerfield, M.R. and McCrae, R.R. (2000). Stress and coping research. Methodological challenges, theor- etical advances, and clinical applications. American Psychologist, 55, $620-625$.

Stewart, S.M. and Schwarzer, R. (1996). Stability of coping in Hong Kong medical students: a longitudinal study. Personality and Individual Differences, 20, 245-255.

Stolte, J.F. (1994). The context of satisficing in vignette research. Journal of Social Psychology, 134, 727-733.

Stone, A.A., Greenberg, M.A., Kennedy-Moore, E. and Newman, M.G. (1991). Selfreport, situation-specific coping questionnaires: what are they measuring? Journal of Personality and Social Psychology, 61, 648-658.

Stone, A.A. and Neale, J.M. (1984). A new measure of daily coping. development and preliminary results.

Journal of Personality and Social Psychology, 46, 892-906.

Tennen, H., Affleck, G., Armeli, S. and Carney, M.A. (2000). A daily process approach to coping. Linking theory, research, and practice. American Psychologist, 55, 626-636.

Van Heck, G.L. and Vingerhoets, A.J.J.M. (1989). Copingstijlen en persoonlijkheidskenmerken [Coping styles and personality characteristics]. Nederlands Tijdschrift voor de Psychologie, 44, 73-87.

Van Sonderen, E. (1991). Het meten van sociale steun [Measuring social support]. Ph.D. Thesis. University of Groningen, Groningen, The Netherlands.

Vitaliano, P.P., DeWolfe, D.J., Maiuro, R.D., Russo, J. and Katon, W. (1990). Appraised changeability of a stressor as a modifier of the relationship between coping and depression: a test of the hypothesis of fit.

Journal of Personality and Social Psychology, 59, 582-592.

Weber, H. (2000). Breaking all the Rules: Impact of Social Norms on Coping. Paper presented at the 14th Conference of the European Health Psychology Society, 16-19 August 2000. Leiden, The Netherlands.

\section{APPENDIX}


Ridder, D. de, Kerssens, J. Owing to the force of circumstances? The impact of situational features and personal characteristics on coping patterns across situations. Psychology \& Health: 2003, 18(2), 217-236

\section{TABLES AND APPENDIX}

TABLE I A taxonomy of situational features

\begin{tabular}{|c|c|c|}
\hline Features & Categories & Referring to \\
\hline \multirow[t]{5}{*}{ Concern at stake } & Attachment & $\begin{array}{l}\text { Situations in which a relationship with an important } \\
\text { other (family, friends) is at stake }\end{array}$ \\
\hline & Control & Situations not allowing for objective control \\
\hline & Predictability & Situations that are new or unpredictable \\
\hline & (Physical) safety & $\begin{array}{l}\text { Situations that bear threat to one's safety by } \\
\text { e.g. violence or illness }\end{array}$ \\
\hline & Competence & $\begin{array}{l}\text { Situations in which one's (intellectual or other) abilities } \\
\text { or skills are questioned }\end{array}$ \\
\hline \multirow[t]{2}{*}{ Ambiguity } & Ambiguous & Situations allowing for multiple interpretations \\
\hline & Unambiguous & Situations that impose their meaning upon the individual \\
\hline \multirow[t]{2}{*}{ Social context } & Private & $\begin{array}{l}\text { Situations in which the individual is alone or in } \\
\text { which family or friends are present }\end{array}$ \\
\hline & Public & $\begin{array}{l}\text { Situations in which 'formal relations' (e.g., colleagues } \\
\text { or unknown people) are present }\end{array}$ \\
\hline
\end{tabular}

TABLE II Elementary features of coping across situations: applicability of coping strategies; range of appraisal and coping strategies across situations; associations between appraisals and coping strategies $(n=430)$

\begin{tabular}{|c|c|c|c|c|}
\hline & \multirow{2}{*}{$\begin{array}{c}\text { Applicability } \\
\text { (mean of \% } \\
\text { yes over } \\
20 \text { situations) }\end{array}$} & \multirow{2}{*}{$\begin{array}{c}\text { Actual employment } \\
\text { in vignette } \\
\text { (averaged over } \\
20 \text { situations) } \\
M(s d)\end{array}$} & \multicolumn{2}{|c|}{$\begin{array}{l}\text { Pearson's product } \\
\text { moment correlations }\end{array}$} \\
\hline & & & Primary appraisal & Secondary appraisal \\
\hline $\begin{array}{l}\text { Primary appraisal } \\
\text { (range } 1-5 \text { ) }\end{array}$ & - & $3.3(1.0)$ & - & $0.54 * *$ \\
\hline $\begin{array}{l}\text { Secondary appraisal } \\
\text { (range } 1-5)\end{array}$ & - & $3.4(0.8)$ & - & - \\
\hline $\begin{array}{l}\text { Confrontation } \\
\text { (range 1-5) }\end{array}$ & $85 \%$ & $2.5(0.4)$ & $0.28 * *$ & $0.29 * *$ \\
\hline $\begin{array}{l}\text { Seeking social support } \\
\text { (range } 1-5 \text { ) }\end{array}$ & $91 \%$ & $2.3(0.6)$ & $0.37 * *$ & 0.10 \\
\hline $\begin{array}{l}\text { Distance } \\
\text { (range 1-5) }\end{array}$ & $97 \%$ & $2.8(0.6)$ & $0.36^{* *}$ & $0.31 * *$ \\
\hline $\begin{array}{l}\text { Escape/avoidance } \\
\text { (range } 1-5 \text { ) }\end{array}$ & $90 \%$ & $2.4(0.7)$ & 0.16 & 0.15 \\
\hline $\begin{array}{l}\text { Accept responsibility } \\
\text { (range 1-5) }\end{array}$ & $86 \%$ & $1.9(0.4)$ & -0.11 & -0.15 \\
\hline $\begin{array}{l}\text { Positive reappraisal } \\
\text { (range } 1-5 \text { ) }\end{array}$ & $89 \%$ & $2.4(0.7)$ & $0.17 *$ & 0.15 \\
\hline $\begin{array}{l}\text { Planful problem solving } \\
\text { (range } 1-5 \text { ) }\end{array}$ & $88 \%$ & $2.8(0.7)$ & $0.32 * *$ & $0.19 * *$ \\
\hline $\begin{array}{l}\text { Self control } \\
\text { (range } 1-5 \text { ) }\end{array}$ & $95 \%$ & $2.8(0.6)$ & $0.25^{* *}$ & $0.17 *$ \\
\hline
\end{tabular}

${ }^{*} p<0.01 ;{ }^{* *} p<0.001$. 
Ridder, D. de, Kerssens, J. Owing to the force of circumstances? The impact of situational features and personal characteristics on coping patterns across situations. Psychology \& Health: 2003, 18(2), 217-236

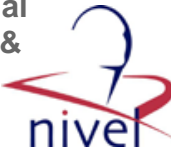

TABLE III Personal coping resources $(n=430)$

\begin{tabular}{lcc}
\hline & Mean & $S D$ \\
\hline GHQ-28 (range 0-28) & 5.3 & 6.0 \\
Self-esteem (range 1-4) & 3.1 & 0.4 \\
Perceived social support (range 1-4) & 3.2 & 0.4 \\
Planful problem solving style (range 1-6) & 4.4 & 0.6 \\
Accept responsibility style (range 1-6) & 3.7 & 0.8 \\
Escape/avoidance style (range 1-6) & 2.9 & 0.9 \\
Positive reappraisal style (range 1-6) & 3.2 & 0.8 \\
Distancing style (range 1-6) & 3.7 & 0.6 \\
Wishful thinking style (range 1-6) & 3.0 & 1.3 \\
Confrontation style (range 1-6) & 3.3 & 1.1 \\
\hline
\end{tabular}

TABLE IV Analysis of variance components for eight coping behaviors $(n=8600)$

\begin{tabular}{lccccc}
\hline Coping strategy & Mean & \multicolumn{5}{c}{ Variance } & $\begin{array}{c}\text { Intraclass } \\
\text { coefficient } \rho \\
\text { between persons/ } \\
\text { total variance) }\end{array}$ \\
\cline { 2 - 5 } & & Total & $\begin{array}{c}\text { Person } \\
\text { (between persons) }\end{array}$ & $\begin{array}{c}\text { Situation } \\
\text { (pooled within) }\end{array}$ \\
\hline Confrontation & 2.82 & 1.20 & 0.29 & 0.91 & 0.24 \\
Seeking social support & 2.79 & 1.72 & 0.23 & 1.49 & 0.14 \\
Distancing & 2.30 & 1.52 & 0.32 & 1.20 & 0.21 \\
Escape/avoidance & 1.97 & 1.57 & 0.13 & 1.44 & 0.08 \\
Accept responsibility & 2.84 & 2.26 & 0.32 & 1.94 & 0.23 \\
Positive reappraisal & 2.39 & 1.95 & 0.45 & 1.49 & 0.05 \\
Planful problem solving & 2.49 & 2.19 & 0.10 & 2.09 & 0.30 \\
Self control & 2.45 & 1.40 & 0.42 & 0.98 & 0.09 \\
Total & 2.51 & 1.80 & 0.17 & 1.64 & \\
\hline
\end{tabular}


TABLE V Multilevel analyses for eight coping behaviors; b's indicating standardized regression coefficients $(n=8600)$

\begin{tabular}{|c|c|c|c|c|c|c|c|c|}
\hline & Confrontation & $\begin{array}{l}\text { Seeking } \\
\text { support }\end{array}$ & Distancing & $\begin{array}{c}\text { Escape/ } \\
\text { avoidance }\end{array}$ & $\begin{array}{c}\text { Accept } \\
\text { responsibility }\end{array}$ & $\begin{array}{l}\text { Positive } \\
\text { reappraisal }\end{array}$ & $\begin{array}{l}\text { Planful problem } \\
\text { solving }\end{array}$ & $\begin{array}{l}\text { Self- } \\
\text { control }\end{array}$ \\
\hline & $b$ & $b$ & $b$ & $b$ & $b$ & $b$ & $b$ & $b$ \\
\hline \multicolumn{9}{|l|}{ Situational characterisitics } \\
\hline Ambiguity (unambiguous vs ref) & $0.05^{*}$ & $-0.10^{*}$ & $0.19 *$ & $0.11 *$ & $0.05^{*}$ & $0.14 *$ & $0.23 *$ & $0.02 *$ \\
\hline Social context (public $v s$ ref) & 0.00 & $-0.04 *$ & $0.05^{*}$ & $-0.12 *$ & $-0.07 *$ & $-0.03 *$ & $0.28 *$ & $-0.03 *$ \\
\hline \multicolumn{9}{|l|}{ Concern at stake (ref. competence) } \\
\hline attachment ( $v s$ ref) & -0.01 & 0.02 & $0.21 *$ & $-0.26^{*}$ & $-0.03 *$ & $0.09^{*}$ & $0.15^{*}$ & 0.02 \\
\hline (physical) safety ( $v s$ ref) & $0.10 *$ & -0.02 & -0.01 & $-0.04 *$ & $-0.13 *$ & $-0.06 *$ & $-0.14 *$ & $0.08 *$ \\
\hline control ( $v s$ ref) & 0.01 & $-0.08 *$ & $0.03 *$ & $-0.28 *$ & $0.06 *$ & $-0.17 *$ & $0.22 *$ & $-0.04 *$ \\
\hline \multicolumn{9}{|l|}{ Personal charactersitics } \\
\hline Sex (male) & 0.01 & 0.02 & $-0.07 *$ & $-0.04 *$ & -0.04 & 0.01 & 0.01 & 0.00 \\
\hline Age & 0.05 & -0.02 & -0.05 & -0.01 & $0.06^{*}$ & $0.11^{*}$ & 0.02 & 0.00 \\
\hline Education & 0.02 & 0.03 & $0.07 *$ & 0.01 & $0.06^{*}$ & -0.04 & -0.02 & $-0.07 *$ \\
\hline GHQ-28 & 0.01 & -0.02 & -0.01 & 0.00 & -0.01 & 0.01 & $0.04 *$ & 0.00 \\
\hline Perceived social support & -0.02 & 0.00 & 0.04 & 0.01 & 0.01 & 0.02 & $0.02 *$ & -0.01 \\
\hline Self-esteem & -0.02 & 0.02 & $-0.07 *$ & $-0.06 *$ & -0.06 & -0.03 & -0.02 & -0.05 \\
\hline Escape/avoidance preference & 0.04 & 0.09 & 0.01 & 0.01 & -0.02 & 0.04 & 0.01 & $0.14 *$ \\
\hline Positive reappraisal preference & 0.03 & -0.03 & $0.05 *$ & 0.02 & $0.07 *$ & $0.11 *$ & $0.05 *$ & -0.04 \\
\hline Distancing preference & 0.03 & 0.02 & $-0.07 *$ & 0.01 & -0.01 & -0.03 & $-0.04 *$ & -0.02 \\
\hline Wishful thinking preference & 0.03 & 0.03 & 0.03 & $0.04 *$ & 0.02 & 0.03 & -0.01 & 0.04 \\
\hline Confrontation preference & -0.02 & -0.04 & $0.06 *$ & 0.03 & -0.01 & 0.00 & $0.03 *$ & -0.02 \\
\hline \multicolumn{9}{|l|}{ Variance components } \\
\hline Person-related variance & 0.27 & 0.21 & 0.24 & 0.10 & 0.27 & 0.40 & 0.11 & 0.37 \\
\hline $\mathrm{R}_{-}$Person-related variance & $6 \%$ & $13 \%$ & $28 \%$ & $26 \%$ & $16 \%$ & $13 \%$ & $17 \%$ & $14 \%$ \\
\hline Situation-related variance & 0.89 & 1.45 & 1.05 & 1.24 & 1.78 & 1.36 & 1.56 & 0.95 \\
\hline$R_{-}$Situation-related variance & $2 \%$ & $3 \%$ & $13 \%$ & $14 \%$ & $8 \%$ & $9 \%$ & $25 \%$ & $3 \%$ \\
\hline
\end{tabular}


Concern: attachment

1 At work, you have an argument with your superior. Your colleagues

Social contex

seem to take your side and support your view. When your

2 You are visiting a reception and having a nice talk with an old friend.

ambiguous

public

When some other people are waving to your friend,

he/she mumbles something and runs off.

3 You are recovering from minor surgery and need to stay at home for a week.

You could use some help but all your friends and family say they have other obligations.

4 You decide to meet an old friend again. When you call for an appointment,

it appears your friend is only vaguely interested in meeting with you again.

Concern: predictability

5 You have been shopping all afternoon and decide to have a break.

In a coffee shop you order a coke and a burger. When your meal is served,

you take a look at the menu and see the price of the burger is 5 euro.

6 You have an appointment with your general practitioner to discuss

some side effects of the medicines he prescribed last week. When you

arrive at the doctor's office, a locum doctor tells you your doctor is not available.

It is a regular working day and you were expecting your partner to be

home at the regular time of $7 \mathrm{pm}$. It is now $9 \mathrm{pm}$ and your partner has not contacted

you yet although it is his/her habit to call you when he/she is late.

8 You have a new job and a colleague invites you for a birthday party at his home.

You are keen on meeting with your new colleagues in an informal setting. When you

arrive, your colleague's family and close friends are the only guests.

Concern : (physical) safety

9 It is late at night when you leave the cinema. A group of noisy adolescents approaches

you and start making comments on your appearance in an aggressive manner.

10 You are waiting for your appointment with the dentist.

You are anxious that a painful treatment is bound to happen.

11 You are driving your car on the freeway singing along with your favorite song on the By miracle you manage to stop the car before it hits another one.

12 You have been suffering from a cold for a while. The last few days you

ambiguous

public

unambiguous

private

ambiguous

private

unambiguous

public

ambiguous

public

unambiguous

private

ambiguous

private

have fits of dizziness and you feel exhausted.

unambiguous

public

ambiguous

public

unambiguous

private

ambiguous

private 


\section{Concern: control}

13 You are taking a walk in the park and witness a father being extremely harsh to his young child. There is nothing you can do to stop him.

14 You are waiting for the plumber who has agreed to fix a leak in your

kitchen at $8 \mathrm{am}$. At $10 \mathrm{am}$ he has not arrived yet and you have an appointment elsewhere.

15 Your neighbors are celebrating a family party. It is already midnight and

you plan to go to sleep, when they decide to turn the music loud and dance.

16 You have planned to finish a job today. A lot of other things keep

coming up and by noon you know that you won't be able to meet your planning.

unambiguous

public

ambiguous

public

unambiguous

private

ambiguous

private

Concern: competence

17 At work a challenging project is available. You just seem the right person to do it and you are eager to apply. However, your superior prefers your colleague.

18 You are taking a course in French conversation and you haven't been able to prepare for the second time this month. Your teacher criticizes you in public.

19 You are determined to save money for the necessary replacement of your washing machine. When you go shopping you see a beautiful but very expensive coat and buy it.

20 You promised a friend to help wallpapering the living room. When you arrive,

it appears your friend is completely depending on your expertise. It is the first time in your life you will be wallpapering.

unambiguous

ambiguous

unambiguous

ambiguous public

public

private

private 